\title{
Microwave Assisted Growth of ZnO Nanorods and Nanopolypods Nanostructure Thin Films for Gas and Explosives Sensing
}

\author{
A. K. Singh ${ }^{1,2}$ \\ ${ }^{1}$ Nanomaterials and Sensors Laboratory, Defence Institute of Advanced Technology, Girinagar, Pune, Maharashtra 411025, India \\ ${ }^{2}$ DRDO Centre for Piezoceramics and Devices, ARDE, Pashan, Pune, Maharashtra 411021, India \\ Correspondence should be addressed to A. K. Singh; aksingh@diat.ac.in
}

Received 16 December 2012; Accepted 2 January 2013

Academic Editor: Amir Kajbafvala

Copyright (C) 2013 A. K. Singh. This is an open access article distributed under the Creative Commons Attribution License, which permits unrestricted use, distribution, and reproduction in any medium, provided the original work is properly cited.

\begin{abstract}
The growth of uniformly distributed and densely packed array of zinc oxide ( $\mathrm{ZnO}$ ) nanorods (NRs) and nanorods (NRs)/nanopolypods (NPPs) was successfully achieved through microwave-assisted chemical route at low temperature. The ZnO NRs and NRs/ NPPs were characterized using X-ray diffraction (XRD), scanning electron microscope (SEM), energy dispersive X-ray analysis (EDX), and UV-Vis absorption spectroscopy. The ZnO NRs were of 100-150 nm diameter and 0.5-1 $\mu \mathrm{m}$ length, while the NPPs were of diameter about $150-200 \mathrm{~nm}$ and $1.5-2 \mu \mathrm{m}$ pod length. The prepared films are polycrystalline in nature and highly oriented along (002) plane with a hexagonal wurtzite structure. These films were studied for the sensing properties of liquefied petroleum gas (LPG), oxygen, and hazardous explosives, that is, 2,4,6-trinitrotoluene (TNT) and cyclotrimethylenetrinitramines (RDX), in the temperature ranges of $25-425^{\circ} \mathrm{C}$ and $100-200^{\circ} \mathrm{C}$, respectively. The grown nanostructure films showed reliable stable response to several on-off cycles, and reduction in sensor recovery time was found with the increase in temperature. ZnO NRs and NRs/NPPs showed better sensitivity and recovery time for both LPG and oxygen, as compared to the literature-reported results for $\mathrm{ZnO}$ thin films.
\end{abstract}

\section{Introduction}

Numerous materials have been reported to be usable as metal-oxide chemical sensors including both single-component (e.g., $\mathrm{ZnO}, \mathrm{SnO}_{2}, \mathrm{WO}_{3}, \mathrm{TiO}_{2}$, and $\mathrm{Fe}_{2} \mathrm{O}_{3}$ ) and multicomponent oxides $\left(\mathrm{BiFeO}_{3}, \mathrm{MgAl}_{2} \mathrm{O}_{4}, \mathrm{SrTiO}_{3}\right.$, and $\mathrm{Sr}_{1-y} \mathrm{Ca}_{y} \mathrm{FeO}_{3-x}$ ). The metal-oxide semiconductors like $\mathrm{ZnO}$, $\mathrm{SnO}_{2}$, or $\mathrm{TiO}_{2}$ react with atmospheres like oxygen, carbon monoxide, or carbon dioxide which has been known for years and investigated intensively. The metal-oxide semiconductors are high gap metal oxides in which the semiconducting behavior arises from the deviation of stoichiometry. Conductometric metal-oxide-semiconductor thin films are the most promising devices among solid state chemical sensors, due to their small dimensions, low cost, low power consumption, on-line operation, and high compatibility with microelectronic processing. The hazardous gas detection spans from environmental monitoring, automotive applications, air conditioning in airplanes, spacecrafts and houses, explosive detection of sensors networks, and so forth. Historically, $\mathrm{ZnO}$ is one of the first materials studied as a gas sensor. $\mathrm{ZnO}$ is also a promising material for the realization of electronic and optoelectronic devices due to its specific chemical, electrical, surface, and microstructural properties. $\mathrm{ZnO}$ is a wide band gap semiconductor, having high exciton binding energy of $60 \mathrm{meV}$ which allows excitonic transitions at room temperature, meaning high radiative recombination efficiency for spontaneous emission as well as lower threshold voltage for emission, and has a stable wurtzite structure with lattice spacing $a=0.325 \mathrm{~nm}$ and $c=0.521 \mathrm{~nm}$. It has attracted intensive research efforts for its unique properties and versatile applications in antireflection coatings, transparent electrodes in solar cells, ultraviolet (UV) light emitters, diode lasers, varistors, piezoelectric devices, spin electronics, surface acoustic wave propagator [1], photonic applications [2], and gas sensing [3].

For gas sensing, $\mathrm{ZnO}$ is good candidate to replace the toxic and expensive materials like $\mathrm{SnO}_{2}$ generally used for 
gas sensing applications [4]. The $\mathrm{ZnO}$ is particularly useful to gas sensors because of its typical properties such as resistivity control over the range of $10^{-3}$ to $10^{5} \Omega \mathrm{m}$, high electrochemical stability, absence of toxicity, and abundant availability in nature [5]. This is primarily due to the high mobility of conduction electrons in the material and good chemical and thermal stability under operating conditions. $\mathrm{ZnO}$-based gas sensors have been fabricated using powders, pellets, thick and thin films, and so forth. Thin films are found to be suitable for such sensors, since the gas sensing properties of metal oxides are related to the material surface and the species are adsorbed and react with the surface $[3,6]$, leading to change in the resistance of sensor element [7]. Instead of the sensors measuring the change of electrical conductance, there are several other kinds of sensors, such as photoluminescence (PL) sensors, nanostructured $\mathrm{ZnO}$ coated quartz crystal microbalance (QCM) sensors, and plasmon surface resonance-based sensors [8]. However, compared with the electrical conductance-based sensors, these sensors are complicated and expensive. The mechanism for gas detection in these conductometric materials is based, in large part, on reactions that occur at the sensor surface, resulting in a change in the concentration of adsorbed oxygen. Variation in conductivity is due to the adsorption of atmospheric oxygen on the oxide surface that extracts electrons from the semiconducting material leading to change in carrier density and conductivity.

The fundamental sensing mechanism of metal-oxidebased gas sensors relies on a change in electrical conductivity due to the interaction process between the surface complexes such as $\mathrm{O}^{-}, \mathrm{O}^{2-}, \mathrm{H}^{+}$, and $\mathrm{OH}^{-}$reactive chemical species and the gas molecules to be detected. For example, changes in the electron density at the semiconductor surface are due to the presence of oxidizing and reducing gases, because of the adsorption and desorption of $\mathrm{O}^{-}, \mathrm{O}^{2-}$, and $\mathrm{O}_{2}{ }^{-}$. Oxygen ions adsorb onto the material's surface, removing electrons from the bulk and creating a potential barrier that limits electron movement and conductivity. On interaction with oxidizing or reducing gases, adsorbed oxygen concentration and thereby conductivity change. The change in conductivity is a measure of gas concentration. For reducing gases such as $\mathrm{H}_{2}$, $\mathrm{H}_{2} \mathrm{~S}, \mathrm{LPG}, \mathrm{CO}, \mathrm{CO}_{2}, \mathrm{C}_{2} \mathrm{H}_{5} \mathrm{OH}$, and $\mathrm{NH}_{3}$, the conductivity increases for $n$-type materials $(\mathrm{ZnO})$ and reduces for $\mathrm{p}$-type materials (such as Te). The effect of oxidizing gases such as $\mathrm{NO}_{2}$ is opposite to that of reducing gases. Adsorbed oxygen gives rise to potential barriers at grain boundaries and thus increases the resistance of sensor surface. On the other hand reducing gas decreases the oxygen surface concentration and hence the surface resistance; magnitude of the response depends on the nature and concentration of the volatile molecules and on the type of metal oxide. This change in conductivity is directly related to the amount of a specific gas present in the environment, resulting in a quantitative determination of gas presence and concentration.

The low selectivity is a well-known problem of these sensors, and its improvement is a research field open to different solutions. An improvement in selectivity can be obtained by changing the sensor temperature during measurements.
These gas-sensor reactions typically occur at elevated temperatures $\left(150-600^{\circ} \mathrm{C}\right)$, requiring the sensors to be internally heated for maximum response. The operating temperature must be optimized for both the sensor material and the gas being detected. In addition, to maximize the opportunities for surface reactions, a high ratio of surface area to volume is needed. As an inverse relationship exists between surface area and particle size, nanoscale materials, which exhibit high surface area, are highly desirable. The effects of the microstructure, namely, ratio of surface area to volume, grain size, and pore size of the metal oxide particles, as well as film thickness of the sensor performance are well recognized. Since the gas sensing mechanism is a surface reaction, use of nanostructured materials is expected to improve gas sensing characteristics. Many recent reports have confirmed the benefits of nanotechnology to sensor performance. The most recent research has been devoted to nanostructured oxides, since reactions at grain boundaries and complete depletion of carriers in the grains can strongly modify the material transport properties. Unfortunately the high temperature required for the surface reactions to take place induces a grain growth by coalescence and prevents the achievement of stable materials.

$\mathrm{ZnO}$ exhibits a wide range of novel structures which include NRs, belts, rings, spheres, and core shells that can be grown by tuning the growth rates along these directions. One of the most profound factors determining the morphology involves the relative surface activities of various growth facets under given conditions. The use of $\mathrm{ZnO}$ nanostructures like NRs, and nanowires, nanotetrapods having higher surface area to volume (aspect ratio) can give even better sensitivity response, compared to $\mathrm{ZnO}$ nanoparticles/thin films, because the interaction between the adsorbed gases and the sensors surface will be stronger for the nanostructures as the complete particle contributes to the gas sensing phenomenon as $D \sim$ $2 L$, where $D$ is the particle diameter and $L$ is the Debye length. The larger surface area of the materials synthesized also facilitates the gas detection at much lower temperatures [9]. The development of $\mathrm{ZnO}$ nanostructure-based gas sensors has attracted intensive research interest in the last several years because of their selective and rapid detection of various gases specified by novel nanostructures. ZnO NRs with excellent gas sensing properties have been reported by Sun et al. [10].

Various $\mathrm{ZnO}$ nanostructures have been prepared using both physical as well as chemical methods, which include chemical vapor deposition [11], physical vapor deposition [12], laser ablation [13], and chemical synthesis [14, 15]. Among them, chemical synthesis is much simpler and the reaction is performed at much lower temperatures [16, 17]. Recently, microwave irradiation has been widely applied to synthesis of nanomaterials. Due to intense friction and the collision of molecules created by microwave irradiation, microwave irradiation not only provides the energy for heating but also greatly accelerates the nucleation. With microwave irradiation on the reactant solution, temperature and concentration gradients can be avoided leading to uniform nucleation. Microwave-based synthesis method is one of the 
easiest, energy-saving, green, and quick methods for largescale production of nanomaterials [18].

Li et al. [19] have used $\mathrm{ZnO}$ nanorods for $\mathrm{H}_{2}, \mathrm{NH}_{3}$, and $\mathrm{C}_{2} \mathrm{H}_{5} \mathrm{OH}$ chemical sensing. Wang et al. [20] have used vertically oriented $\mathrm{ZnO}$ nanorods for $\mathrm{H}_{2}$ sensing and have also reported detection of $\mathrm{NH}_{3}$ and $\mathrm{CO}$. Sun et al. [10] have used $\mathrm{ZnO}$ nanorods for $\mathrm{H}_{2}, \mathrm{NH}_{3}$, LPG, and $\mathrm{CH}_{3} \mathrm{CH}_{2} \mathrm{OH}$ whereas $\mathrm{Lv}$ et al. [21] reported use of $\mathrm{ZnO}$ nanorods for benzene and ethanol gas. Zhang et al. [22] have synthesized 3D microspheres for ethanol and ammonia sensing. Baratto et al. [23] have used $\mathrm{ZnO}$ nanostructured fibers for $\mathrm{NO}_{2}$ sensing. Kenanakis et al. [24] have synthesized $\mathrm{ZnO}$ nanosponge/rod for ozone detection. Recently, Choi and Jang [25] have reviewed the use of $1 \mathrm{D}$ oxide nanostructures for chemical sensing. To the author's knowledge there is hardly any report on the usage of $\mathrm{ZnO}$ NRs and NPPs for explosive sensing. In the present paper, $\mathrm{ZnO}$ NRs and $\mathrm{ZnO}$ NRs/NPPs were grown on glass substrate using microwave-assisted chemical synthesis method. The gas (LPG and oxygen) and $\mathrm{RDX}$ and TNT explosive sensing properties of $\mathrm{ZnO}$ NRs and NRs/NPPs have been investigated.

\section{Experimental}

All substrates were thoroughly cleaned by the following sequence: cleaned by labolene detergent and then rinsed with double-distilled (DD) water; then boiled with dilute chromic acid for 15 minutes and thoroughly rinsed with DD water; after that, ultrasonicated for $10 \mathrm{~min}$ in acetone and then in methanol, and finally all substrates were dried in an oven.

The ZnO NRs and NPPs on glass substrates were grown using microwave-assisted chemical method in place of conventional heating [26]. The growth of $\mathrm{ZnO}$ NRs was carried out in two steps.

2.1. First Step: Synthesis of $\mathrm{ZnO}$ Seed Layer. Two samples of $\mathrm{ZnO}$ sol were prepared, one without capping agent and another with triethanolamine (TEA) as capping agent. In the first case (without capping agent), solution of $0.03 \mathrm{M}$ sodium hydroxide $\left(\mathrm{NaOH}\right.$, Merck) in methanol $\left(\mathrm{CH}_{3} \mathrm{OH}\right.$, Merck) was added slowly to a continuously stirred solution of $0.01 \mathrm{M}$ zinc acetate dihydrate $\left(\mathrm{CH}_{3} \mathrm{COO}\right)_{2} \mathrm{Zn} \cdot 2 \mathrm{H}_{2} \mathrm{O}$ (Merck) in methanol at $60^{\circ} \mathrm{C}$. The formed sol is designated as sample S1 hereafter. In the second case, $0.24 \mathrm{~mL}$ TEA (Merck) was added after a gap of $5 \mathrm{~min}$ to a continuously stirred solution of $0.03 \mathrm{M}$ sodium hydroxide and $0.01 \mathrm{M}$ zinc acetate dihydrate $\left(\mathrm{CH}_{3} \mathrm{COO}\right)_{2} \mathrm{Zn} \cdot 2 \mathrm{H}_{2} \mathrm{O}$ in methanol at $60^{\circ} \mathrm{C}$. The formed sol is designated as sample S2 hereafter. For the growth of $\mathrm{ZnO}$ nanoparticles, the operation temperature of solution was uniformly maintained at $60^{\circ} \mathrm{C}$ for $01 \mathrm{~h}$, using $2.54 \mathrm{GHz}$ microwave radiations. The 5 min delay in addition of TEA resulted in the formation of $\mathrm{ZnO}$ and $(\mathrm{ZnOH})^{+}$ cations from the chemical reaction of zinc acetate dihydrate and sodium hydroxide and prevented the agglomeration of colloidal particles.

The prepared sol S1 and S2 were spin-cast four times on glass substrate at $3000 \mathrm{RPM}$ for $20 \mathrm{~s}$ each time to form uniform $\mathrm{ZnO}$ seed layer. Between coatings, the substrates were annealed in open air at $150^{\circ} \mathrm{C}-160^{\circ} \mathrm{C}$ for $15 \mathrm{~min}$ to ensure particle adhesion onto the substrate surface.

2.2. Second Step: Growth of ZnO NRs and NPPs. Growth of NRs and NPPs was carried out by suspending the substrates with crystal seed layer upside down in an aqueous solution containing $0.025 \mathrm{M}$ Zinc nitrate hexahydrate, $\mathrm{Zn}\left(\mathrm{NO}_{3}\right)_{2} \cdot 6 \mathrm{H}_{2} \mathrm{O}$ (Merck), $2.58 \mathrm{~mL}$ of diethylenetriamine, and $\mathrm{C}_{4} \mathrm{H}_{13} \mathrm{~N}_{3}$ (Burgoyne Mk) in $\mathrm{DD}$ water at $90^{\circ} \mathrm{C}$. The required operation temperature was maintained using $2.54 \mathrm{GHz}$ microwave radiations. After $5 \mathrm{hrs}$ the substrates were removed, rinsed thoroughly with DD water, and dried at room temperature. The prepared $\mathrm{ZnO}$ film on glass substrate without capping agent is defined as "F1" and another with capping agent defined as "F2."

The prepared samples S1-S2 and films F1-F2 were characterized at different stages of synthesis and growth. The UVVis spectroscopy of samples was done in the range of about $300-700 \mathrm{~nm}$ with the help of spectrometers (NanoDrop-1000 and HPX-2000). The particles size of $\mathrm{ZnO}$ nanoparticles was measured using particle sizing system (Nicomp-380ZLS). The structural and morphological study of samples was carried out using Xpert PRO Panalytical Powder X-ray diffractometer (XRD) in the scanning range of $20-80^{\circ}(2 \theta)$ using $\mathrm{Cu} \mathrm{K}_{\alpha}$ radiations with wavelength $1.54 \AA$ (JOEL, JSM-6360A, and Philips XL-30) and analytical scanning electron microscope (SEM).

The gas (LPG and oxygen) and explosives sensing properties of film $\mathrm{F} 1$ ( $\mathrm{ZnO}$ nanorods, NRs) and film F2 ( $\mathrm{ZnO}$ nanopolypods, NPPs) samples was carried out in a custom designed gas sensor assembly [3]; it comprises a temperature controller, a copper-constantan thermocouple, an electric heating plate, a gas chamber, and a volume measurement unit. The two-probe DC measurement technique was used to measure the electrical resistance in air and in the presence of target gas at constant voltage of $6 \mathrm{~V}$. For electric measurements, silver paste contacts separated by a gap of $5 \mathrm{~mm}$ were used to form ohmic contacts on the films F1 and F2. The electrical resistance of film F1 or F2 in air $\left(R_{a}\right)$ and in the presence of target gas $\left(R_{g}\right)$ was measured to evaluate the sensor response/sensitivity $(S)$, percentage sensor sensitivity $(S \%)$, and recovery time $(t)$ as follows [27]:

$$
\begin{gathered}
S=\frac{R_{g}}{R_{a}}, \\
S \%=(1-S) \times 100, \\
t=t_{2}-t_{1},
\end{gathered}
$$

where $t_{1}$ is the moment the target gas is switched off and $t_{2}$ is the moment the sample regains its initial resistance, while the difference of both these times gives the recovery time.

\section{Characterization}

3.1. UV-Visible Absorption Spectra and Particle Size of $\mathrm{ZnO}$ Nanoparticles. Figure 1 shows UV-Visible absorption spectra 


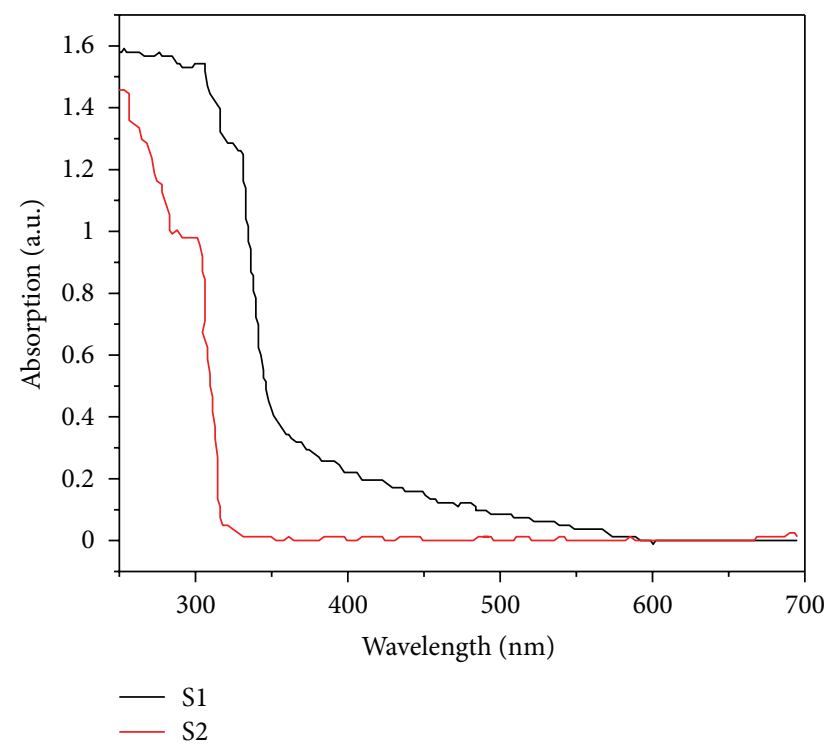

FIGURE 1: UV-Vis absorption spectra of $\mathrm{ZnO}$ nanoparticles of samples S1 and S2.

of the samples S1 and S2. It is clear from the figure that the absorbance peak for sample S1 is at $329 \mathrm{~nm}$ and for S2 is at $302 \mathrm{~nm}$. The blue shift in the optical absorption can be attributed to the use of TEA as a capping agent. Similar result has been reported by Singh et al. [28]. To confirm the blue shift in the optical absorption particle size distribution was recorded on the particle size analyzer and is shown in Figure 2. The particle size distribution for the sample S1 was observed to be around $942 \mathrm{~nm}$ whereas for S2, $190 \mathrm{~nm}$ as can be seen from Figure 2. The agglomeration of particles was noticed in the case of $S 1$ as evident from Figure 2(a). Thus the blue shift is supported by the size distribution analysis. Reduction of the particle size from $942 \mathrm{~nm}$ to $190 \mathrm{~nm}$ was observed in the case of $\mathrm{S} 2$ because of TEA which prevents the agglomeration.

3.2. UV-Vis Optical Absorption of $\mathrm{ZnO}$ Nanostructures. Figure 3 shows the UV-Vis optical absorption spectra of films F1 and F2 with absorption edge at $373 \mathrm{~nm}$ and $370 \mathrm{~nm}$, respectively. These values are found to be less than $380 \mathrm{~nm}$ which corresponds to bulk $\mathrm{ZnO}$, indicating that $\mathrm{ZnO}$ nanostructures grown are smaller than bulk $\mathrm{ZnO}$ particles [29].

3.3. Structural Analysis. Figures 4(a) and 4(b) show the Xray diffraction patterns for the films $\mathrm{F} 1$ and $\mathrm{F} 2$, respectively. The diffraction peaks observed at $32.4^{\circ}, 34.4^{\circ}, 36.7^{\circ}, 48.2^{\circ}$, $57.3^{\circ}$, and $63.6^{\circ}$ are attributed to the (100), (002), (101), (102), (110), and (103) planes, respectively, of hexagonal wurtzite structure [30], as can be seen in comparison with the JCPDS card nos. 00-003-0752/01-075-1526 and 01-077-2414 for F1 and F2. Both the films F1 and F2 are polycrystalline in nature and highly oriented along (002) plane. The crystallite sizes were calculated using Scherrer's formula using information

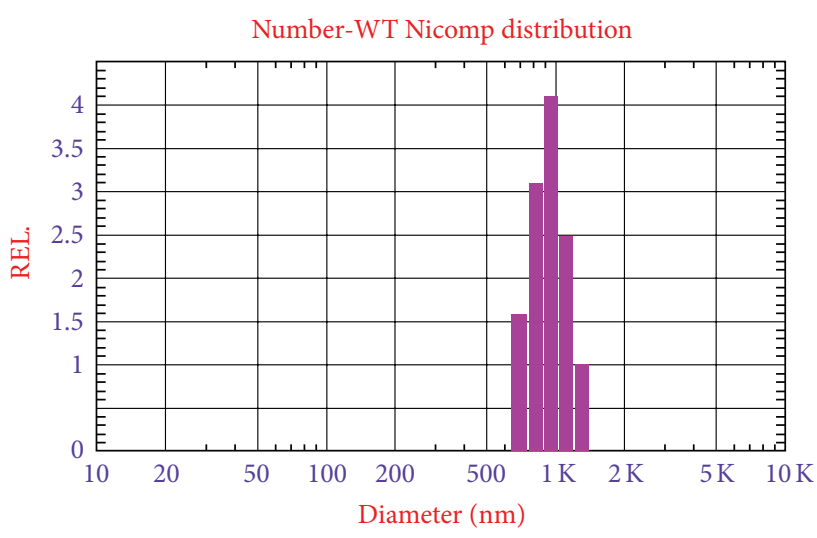

(a)

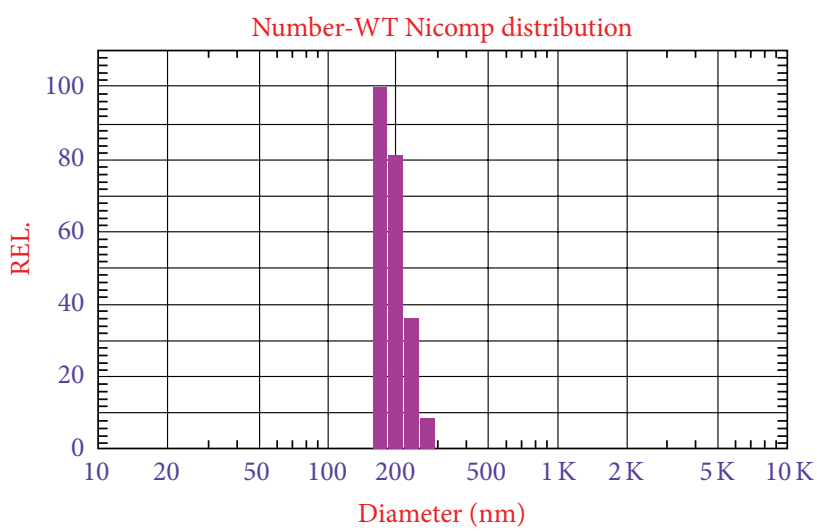

(b)

FIgURE 2: Particles size distribution of $\mathrm{ZnO}$ nanoparticles (based on number-weight distribution): (a) without capping agent sample S1 (Av. particle size: $942 \mathrm{~nm}$ ) and (b) with capping agent sample S2 (Av. particle size: $190 \mathrm{~nm}$ ).

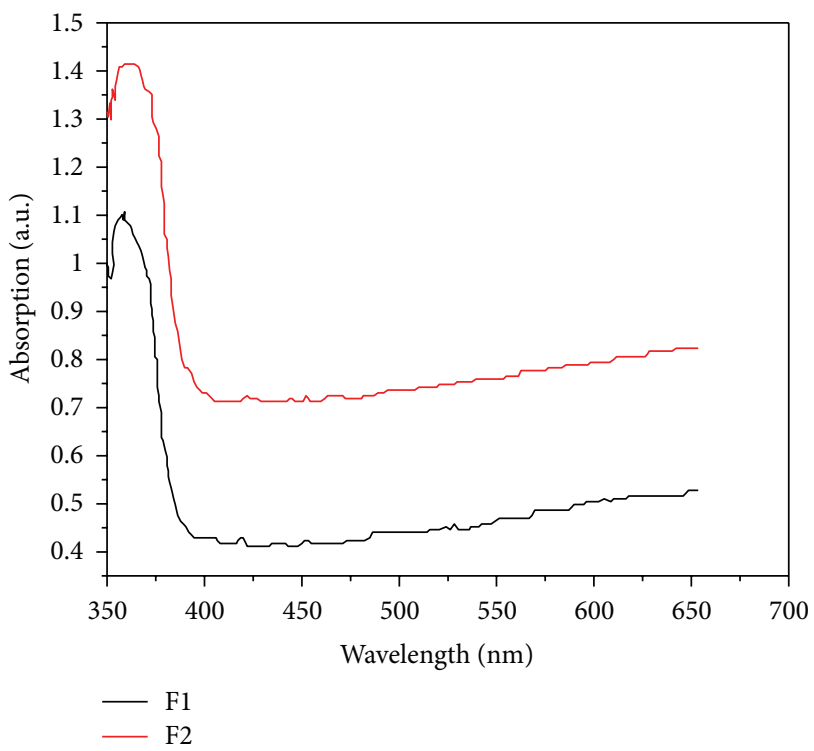

Figure 3: Optical absorption spectra of $\mathrm{ZnO}$ films F1 and F2. 


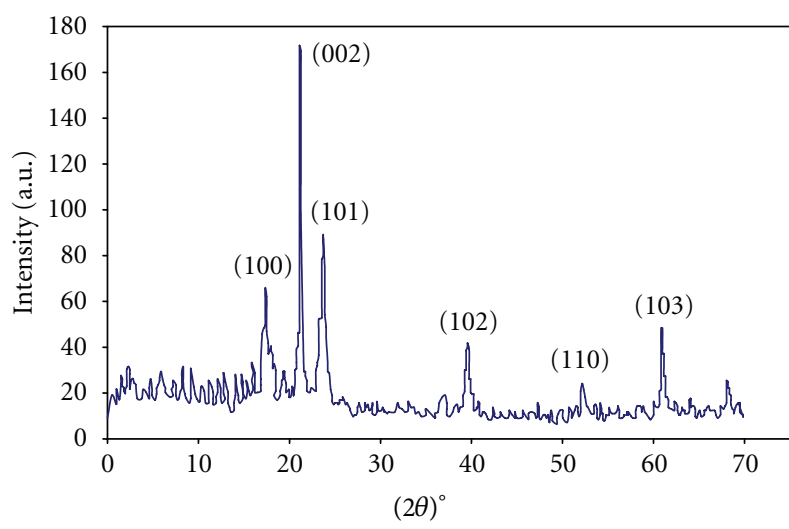

(a)

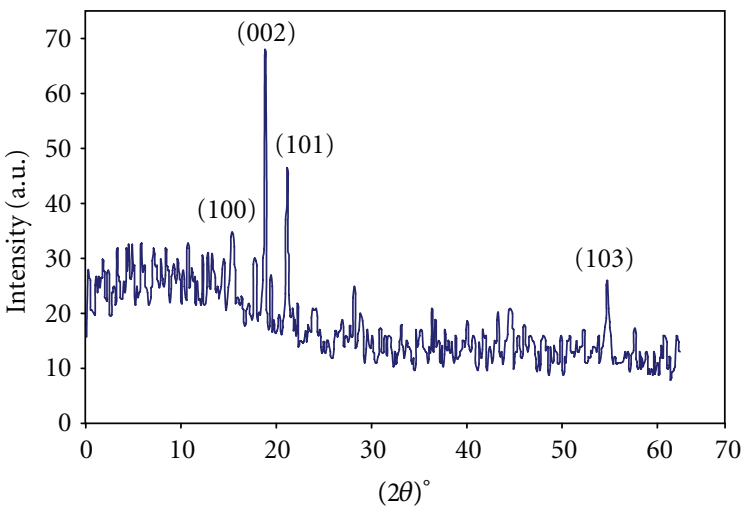

(b)

Figure 4: XRD of (a) ZnO film F1 and (b) ZnO film F2.

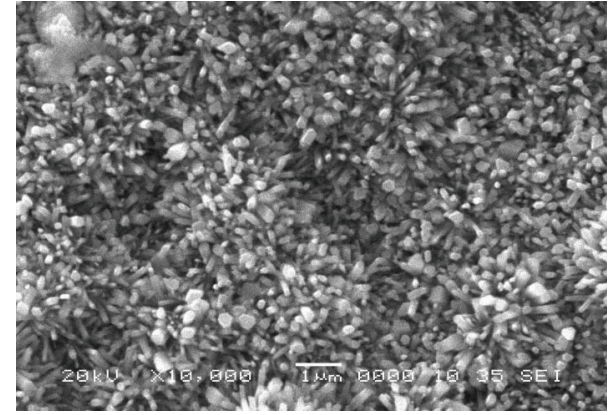

(a)

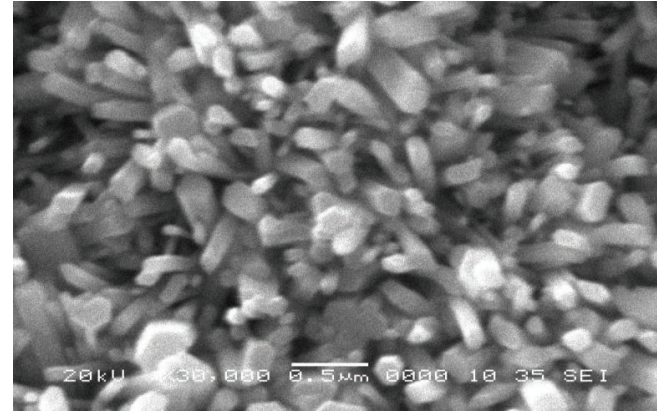

(b)

Figure 5: SEM images of ZnO film F1: (a) ZnO nanorods (NRs) with scale $1.0 \mu \mathrm{m}$ and (b) enlarged view of nanorods (NRs) with scale $0.5 \mu \mathrm{m}$.

on broadening of diffraction peak $(\beta)$, X-ray wavelength $(\lambda)$, and incident $\mathrm{X}$ ray angle with crystal plane $\left(\theta_{B}\right)$, that is,

$$
T=\frac{0.9 \lambda}{\beta \cos \theta_{B}} .
$$

The average crystallite size for the (100), (002), and (101) XRD peaks was found to be between $35-105 \mathrm{~nm}$ and $35-141 \mathrm{~nm}$ for $\mathrm{F} 1$ and F2 films, respectively.

3.4. Surface Morphology of Nanostructures. Figures 5 and 6 shows the SEM micrographs of the samples F1 and F2, respectively. From Figures 5(a) and 5(b) one can see the growth of uniform and densely packed array of $\mathrm{ZnO}$ NRs with diameter $100-150 \mathrm{~nm}$ and length $0.5-1 \mu \mathrm{m}$. Figures 6(a)-6(c) show growth of $\mathrm{ZnO}$ NPPs over uniform and densely packed array of NRs which is shown in Figure 6(d). The NPPs are with pod diameter about $150-200 \mathrm{~nm}$ and pod length $1.5-$ $2 \mu \mathrm{m}$. The formation of NPPs in sample F2 may be attributed to the addition of TEA as capping agent [31].

\section{Gas Sensing}

4.1. Effect of Temperature on Sensor Response for $L P G$ and Oxygen. Figures 7(a), 7(b), 8(a), and 8(b) show the sensor response $(S)$ as a function of temperature for films F1 and $\mathrm{F} 2$ over the temperature range from ambient $25^{\circ} \mathrm{C}$ to about $425^{\circ} \mathrm{C}$, at three different concentrations of $0.2 \mathrm{vol} . \%$, $0.32 \mathrm{vol} . \%$, and $0.4 \mathrm{vol} . \%$ of LPG and oxygen, respectively. The response to the LPG and oxygen is due to oxygen vacancies on metal-oxide $(\mathrm{ZnO})$ surfaces, which are electrically and chemically active. These vacancies function as $\mathrm{n}$-type donors and often significantly increase the conductivity of oxide. Initially, the sensor response $(S)$ increases with the increase in temperature and reaches a maximum value for both samples with the gases. Observation of Figures 7(a) and 7(b) shows that for LPG the sensor response reaches the maximum value at $385^{\circ} \mathrm{C}$ temperature for film $\mathrm{F} 1$, while for $\mathrm{F} 2$ the maximum value lies in the range from $280^{\circ} \mathrm{C}$ to $345^{\circ} \mathrm{C}$; similar behavior has been reported by Patil et al. [32], Shinde et al. [4], and Sun et al. [10]. Observation of Figures 8(a) and 8(b) shows that for oxygen the sensor response reaches the maximum value at temperatures of $405^{\circ} \mathrm{C}, 385^{\circ} \mathrm{C}$, and $380^{\circ} \mathrm{C}$ for film $\mathrm{F} 1$, while for $\mathrm{F} 2$ the maximum response is at $195^{\circ} \mathrm{C}, 270^{\circ} \mathrm{C}$, and $275^{\circ} \mathrm{C}$. This temperature is called optimal temperature, and activation energy at this temperature may be enough to complete the chemical reaction, which results in the maximum adsorption of the concerned gas, and above the optimal temperature the sample temperature increases and it causes a decrease in the sensitivity $(S)$, indicating the rate of 


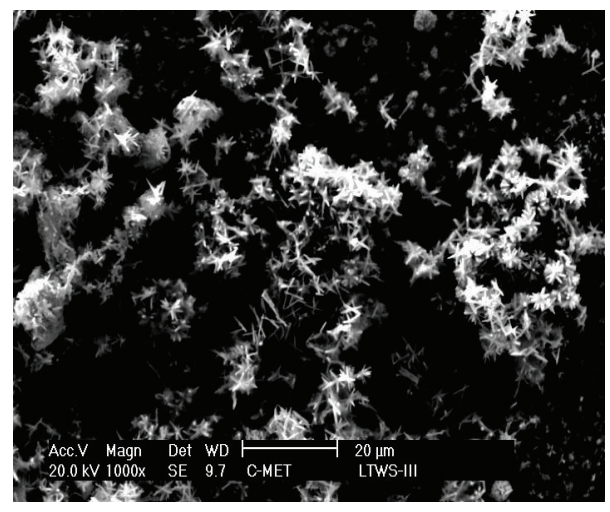

(a)

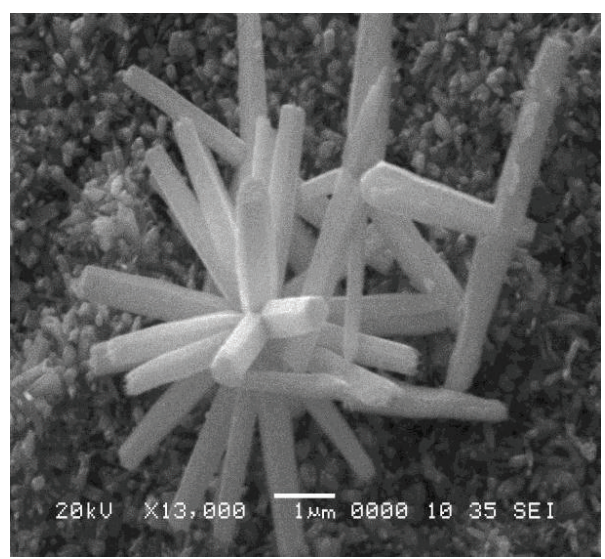

(c)

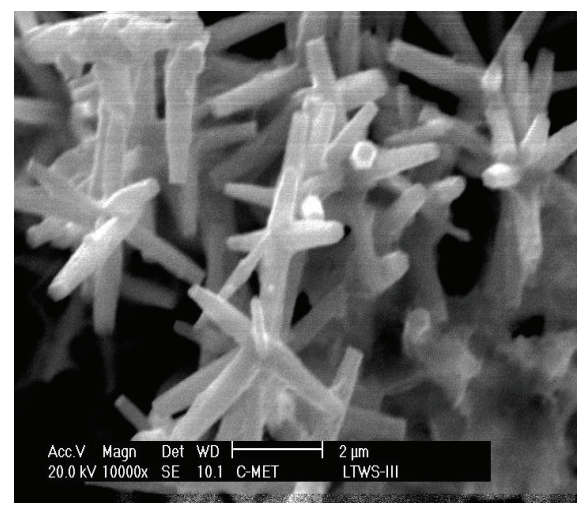

(b)

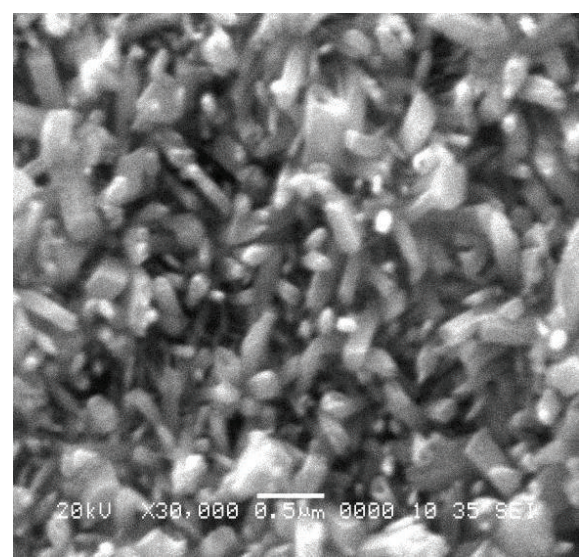

(d)

FiguRE 6: SEM images of ZnO of film F2: (a) ZnO nanopolypods (NPPs) with scale $20.0 \mu \mathrm{m}$, (b) enlarged view of nanopolypods (NPPs) with scale $2.0 \mu \mathrm{m}$, (c) nanopolypods (NPPs) with nanorods (NRs) in the background with scale $1.0 \mu \mathrm{m}$, and (d) enlarged view of ZnO nanorods (NRs) with scale $0.5 \mu \mathrm{m}$.

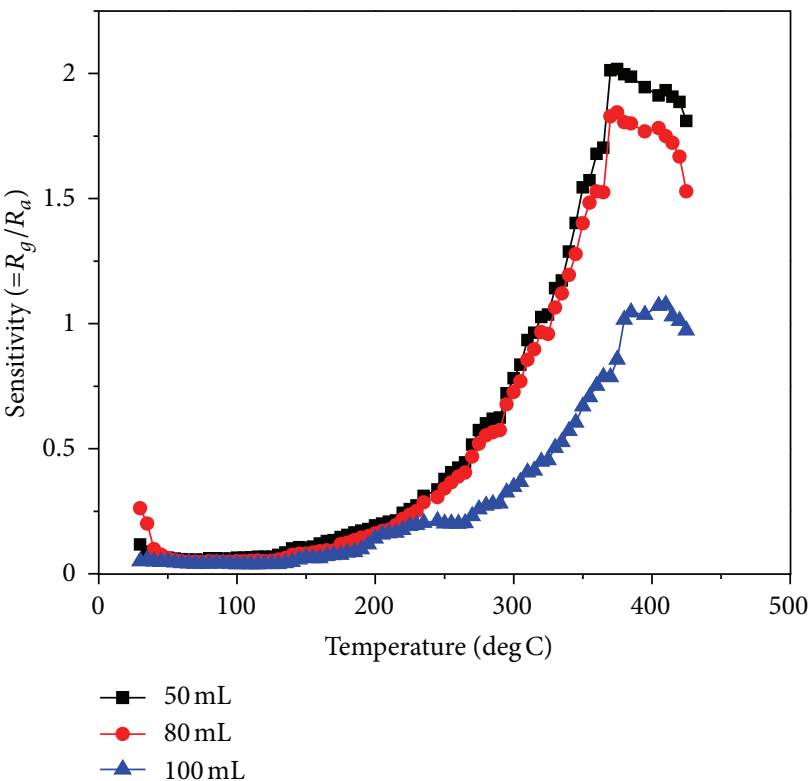

(a)

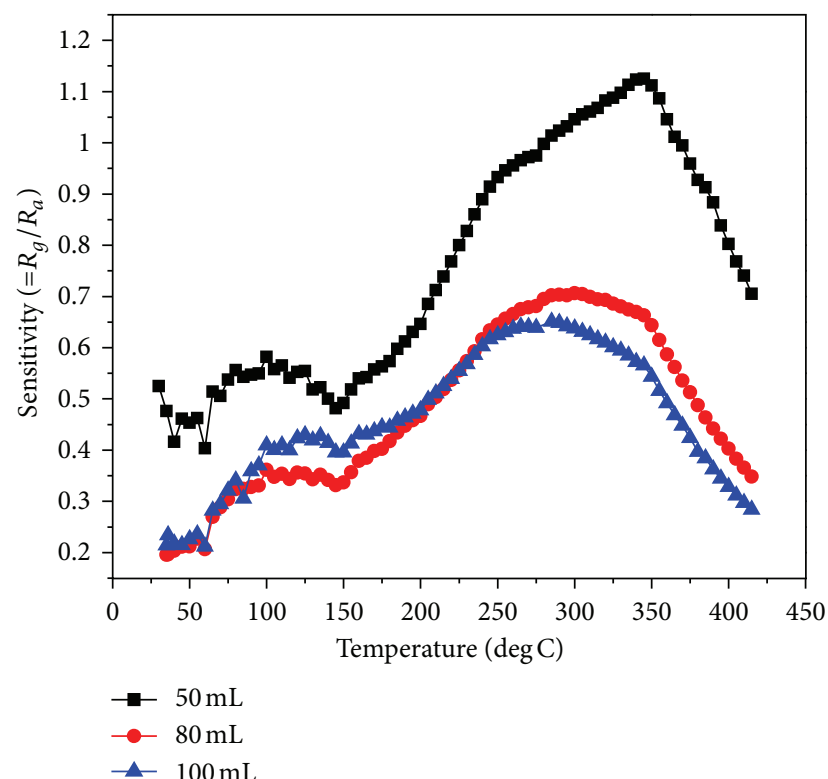

(b)

FIGURE 7: Sensor response $\left(R_{g} / R_{a}\right)$ with temperature for LPG: (a) ZnO nanorods (NRs) film F1 and (b) ZnO nanopolypods (NPPs) film F2. 


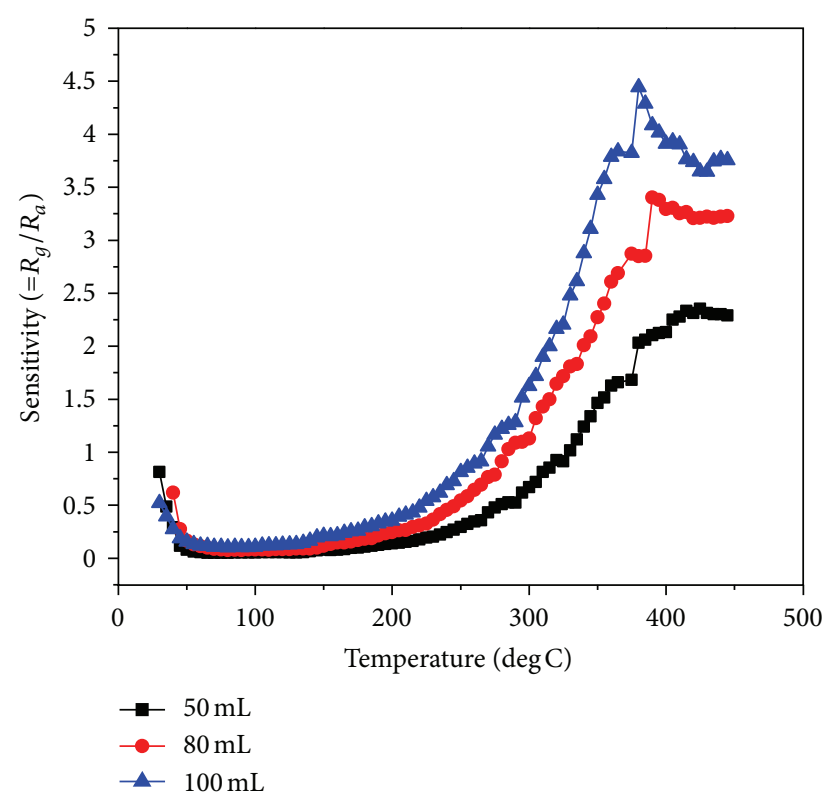

(a)

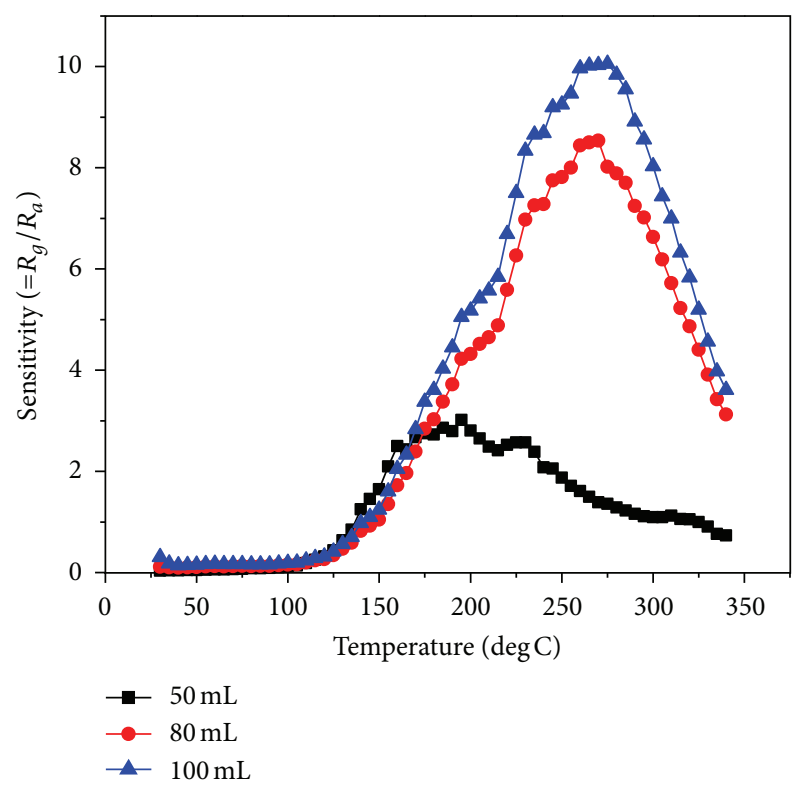

(b)

FIGURE 8: Sensor response $\left(R_{g} / R_{a}\right)$ with temperature for oxygen gas: (a) $\mathrm{ZnO}$ nanorods (NRs) film $\mathrm{F} 1$ and (b) $\mathrm{ZnO}$ nanopolypods (NPPs) film F2.

desorption of the reducing gas. The increase and decrease in the sensitivity observed in the figures indicate the adsorption and desorption phenomenon of the gases. The change in resistance of a semiconductor oxide like $\mathrm{ZnO}$ sensors in the presence of target gas takes place according to two reactions [33]. In the first reaction, atmospheric or injected oxygen $\mathrm{O}_{2}$ molecules are adsorbed onto the surface by taking electron from the conduction band and are thus chemisorbed on the surface as $\mathrm{O}_{\text {ads }}^{-}$; this leads to an increase in the resistance of

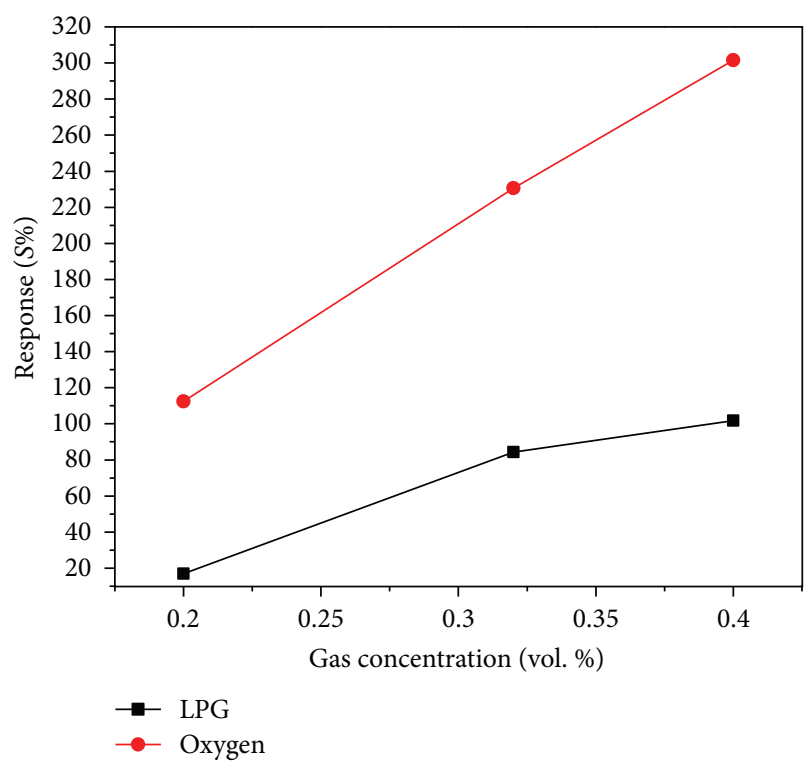

FIGURE 9: Percentage sensor sensitivity (S\%) with LPG and oxygen concentration (vol.\%) at $385^{\circ} \mathrm{C}$ for $\mathrm{ZnO}$ nanorods (NRs) film F1.

the sensor material. The chemical reaction can be explained by the following equation:

$$
\mathrm{O}_{2}(\mathrm{~atm})+2 \mathrm{e}^{-}(\mathrm{cb}) \longrightarrow 2 \mathrm{O}_{\mathrm{ads}}^{-}
$$

In the second reaction, the reducing gases $(\mathrm{R})$ present in the ambient air or injected into the reaction chamber react with the chemisorbed oxygen $\mathrm{O}_{\text {ads }}^{-}$thereby releasing an electron back to the conduction band and decreasing the resistance of the sensor material given by the following equation:

$$
\begin{gathered}
\mathrm{R}+\mathrm{O}_{\text {ads }}^{-} \longrightarrow \mathrm{RO}+\mathrm{e}^{-} \\
\mathrm{C}_{n} \mathrm{H}_{2 n+2}+2 \mathrm{O}^{-} \longleftrightarrow \mathrm{H}_{2} \mathrm{O}+\mathrm{C}_{n} \mathrm{H}_{2 n}-\mathrm{O}+\mathrm{e}^{-}
\end{gathered}
$$

As LPG consists of $\mathrm{CH}_{4}, \mathrm{C}_{3} \mathrm{H}_{8}, \mathrm{C}_{4} \mathrm{H}_{10}$, and so forth, in these molecules the reducing hydrogen species are bound to carbon atoms. The overall reaction of LPG molecules with adsorbed oxygen can be explained in a similar way by the previous equation.

In case of oxygen, the maximum sensitivity value increases with the increase in gas concentration, whereas for LPG the maximum sensitivity value reduces with the increase the in concentration of gas. This opposite behavior is due to LPG and oxygen being reducing and oxidizing gases, respectively.

4.2. Effect of Gas Concentration on Sensor Response. Figure 9 shows the sensor response (S\%) of film F1 as a function of $\mathrm{LPG} /$ oxygen concentration at $385^{\circ} \mathrm{C}$; it reveals that the sensor percentage sensitivity ( $S \%$ ) increases from nearly $17 \%$ to $102 \%$ for LPG and $106 \%$ to $329 \%$ for oxygen as the concentration of gas increased from 0.2 vol. \% to 0.4 vol. \%; similar increasing behavior has been reported for LPG by Shinde et al. [4]. As the LPG gas concentration increased from $0.2 \%$ to 0.32 vol. $\%$, the response increased rapidly from $17 \%$ to $84 \%$, but at a 


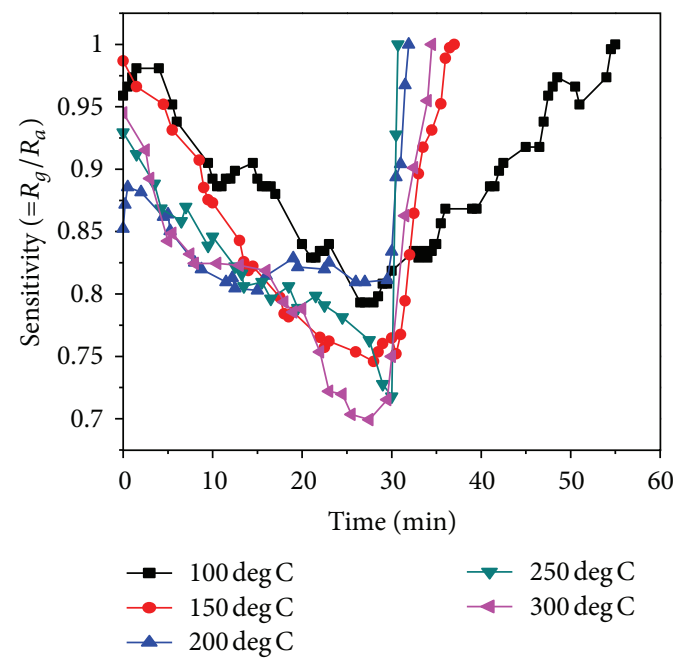

(a)

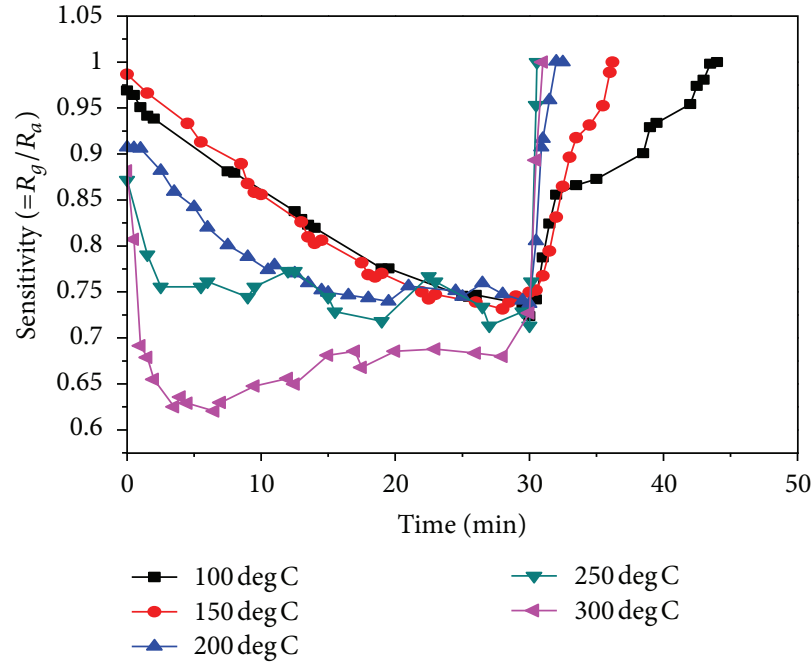

(b)

FIGURE 10: Sensing and recovery time for LPG: (a) ZnO nanorods (NRs) film F1 and (b) ZnO nanopolypods (NPPs) film F2.

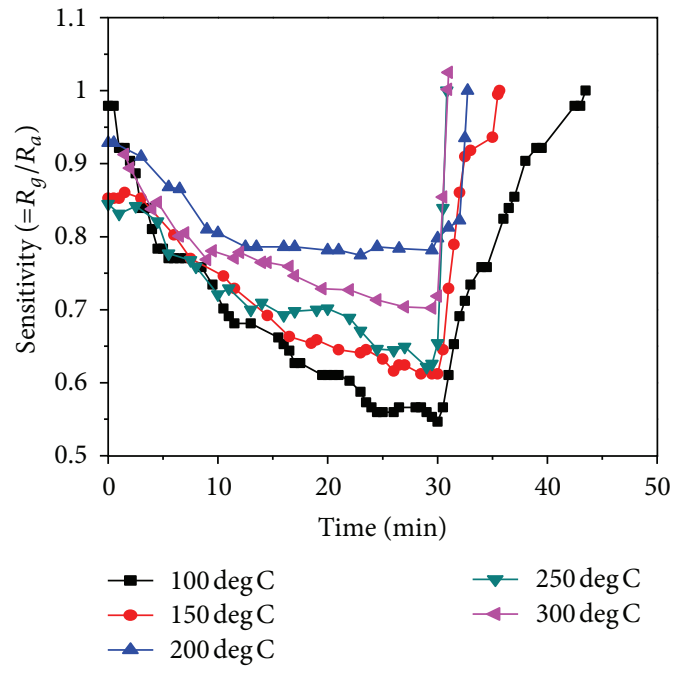

(a)

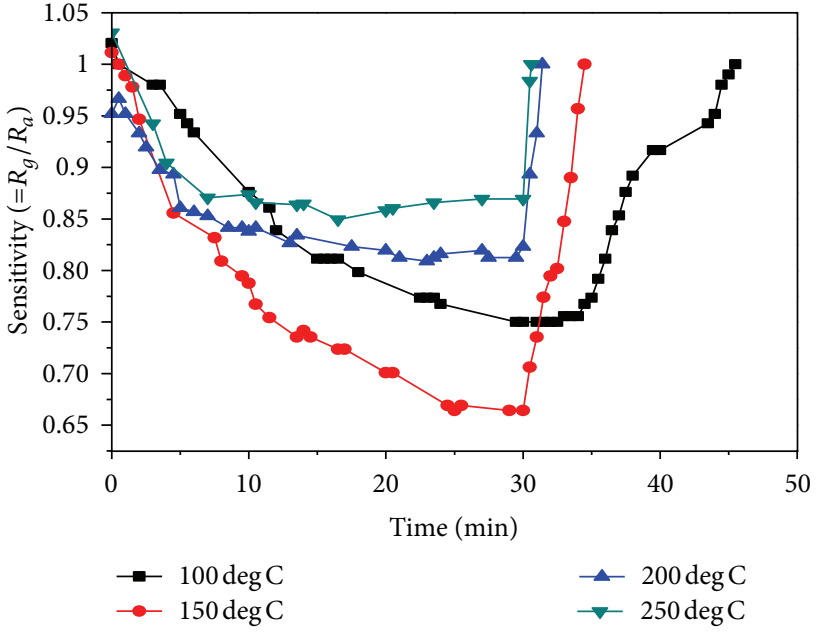

(b)

FIGURE 11: Sensing and recovery time for oxygen gas: (a) ZnO nanorods (NRs) film F1 and (b) ZnO nanopolypods (NPPs) film F2.

higher concentration the increase in gradual response has been observed and after which it gets saturated; however, a linear variation has been observed in the case of oxygen. The response can be explained on the basis of the removal of adsorbed oxygen molecules by reaction with the target gas and generation of electrons. For a small concentration of gas, exposed on a fixed surface area of a sample, there is a lower coverage of gas molecules on the surface and hence lower surface reaction, while for an increase in gas, concentration increases the surface reaction due to a larger surface coverage. A further increase in surface reaction will be gradual when the saturation point on the coverage of molecules is achieved [33].
4.3. Sensor Recovery Analysis for LPG and Oxygen. Figures 10(a), 10(b), 11(a), and 11(b) show the sensor sensitivity (S) to LPG and oxygen with time at fixed temperatures for films F1 and F2, respectively. The sensor sensitivity $(S)$ for films F1 and F2, during exposure to 0.4 vol.\% of LPG/oxygen in an airtight chamber for $30 \mathrm{~min}$ and thereafter recovery in air, was observed at fixed temperatures of $100^{\circ} \mathrm{C}, 150^{\circ} \mathrm{C}, 200^{\circ} \mathrm{C}$, $250^{\circ} \mathrm{C}$, and $300^{\circ} \mathrm{C}$. The sensor sensitivity $(S)$ for both samples decreases with time in the presence of LPG/oxygen due to the desorption process of reducing gas species present in the LPG and the ambient air $[4,7]$. After $30 \mathrm{~min}$, the recovery time was checked by the immediate exposure of sample to ambient air. It shows that the recovery time $(t)$, defined by (3), reduces 
TABLE 1: Comparison table of sensitivity $(S \%)$ and recovery time $(t)$ for films F1 and F2 for LPG.

\begin{tabular}{lcccc}
\hline \multirow{2}{*}{ Temperature $\left({ }^{\circ} \mathrm{C}\right)$} & \multicolumn{2}{c}{ ZnO nanorods (NRs) (F1) } & \multicolumn{2}{c}{ ZnO nanopolypods (NPPs) (F2) } \\
& Percentage of sensor sensitivity $(S \%)$ & Recovery time (min) & Percentage of sensor sensitivity (S\%) & Recovery time (min) \\
\hline 100 & 18.2 & 25 & 27.7 & 14 \\
150 & 33.3 & 2.9 & 25 & 6.2 \\
200 & 17 & 1.9 & 26.3 & 2.5 \\
250 & 28.2 & 0.7 & 28.7 & 0.66 \\
300 & 25 & 2.75 & 27.3 & 1.0 \\
\hline
\end{tabular}

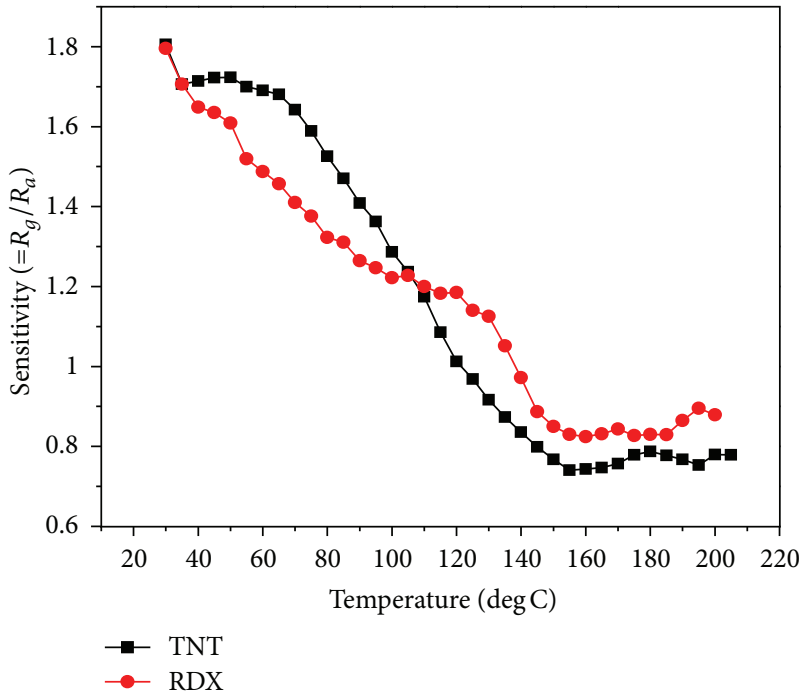

FIGURE 12: Sensitivity response with temperature in the presence of TNT/RDX, for film F1.

with an increase in operation temperature up to $250^{\circ} \mathrm{C}$ and thereafter increases for higher temperatures. The recovery of the resistance when target gas is removed is determined by both oxygen readsorption from the ambient on the surface and reoxidation of the oxide. The films F1 and F2 sensitivity $(S)$ response and recovery patterns achieved for LPG are similar and with better recovery time, in comparison to those reported by Chatterjee et al. [7] for higher concentration (2 vol\%) of LPG on $\mathrm{ZnO}$ thin film. Tables 1 and 2 show the comparison of percentage sensor sensitivity $(S \%)$ and recovery time $(t)$ of films F1 and F2 for both LPG and oxygen. At temperature $250^{\circ} \mathrm{C}$ both films have shown the least recovery time for both LPG and Oxygen. Also the LPG recovery time achieved at $150^{\circ} \mathrm{C}$ for both films is much lesser than that reported by Chatterjee et al. [7] using $\mathrm{ZnO}$ thin films.

\section{Explosives Sensing}

5.1. TNT and RDX Explosives Sensing. Explosives are chemical compounds that can be initiated to undergo selfpropagating decomposition resulting in the sudden release of heat and pressure [34]. The TNT $\left[\left(\mathrm{C}_{6} \mathrm{H}_{2}\left(\mathrm{NO}_{2}\right)_{3} \mathrm{CH}_{3}\right]\right.$ and $\mathrm{RDX}\left[\left(\mathrm{CH}_{2}-\mathrm{N}-\mathrm{NO}_{2}\right)_{3}\right]$ belong to a class of nitroaromatic and nitramines compounds and have extremely low vapour pressure of $4.8 \times 10^{-6}$ (Torr) and $8.3 \times 10^{-10}$ (Torr) at $20^{\circ} \mathrm{C}$, respectively. Nanostructures such as NRs and nanoparticles

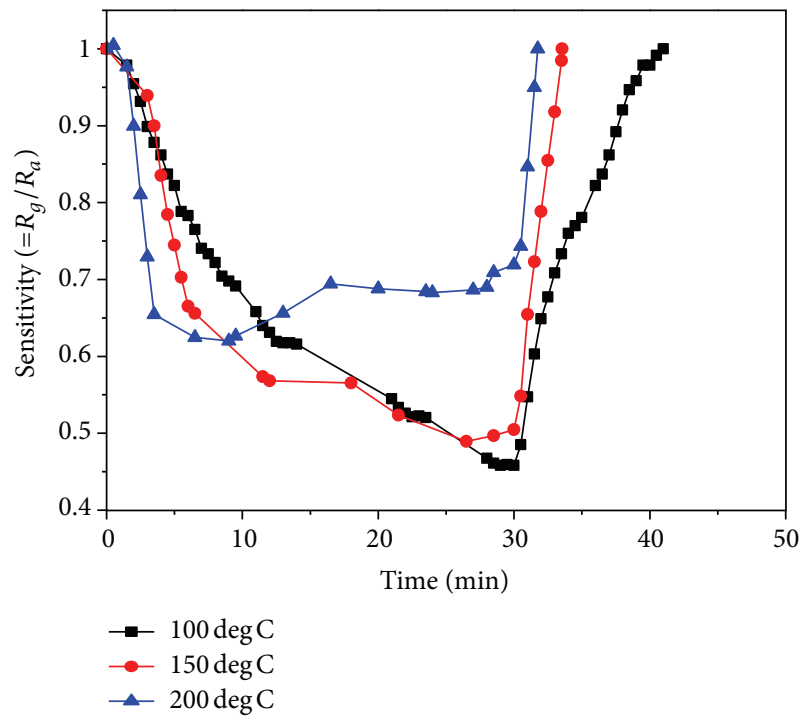

(a)

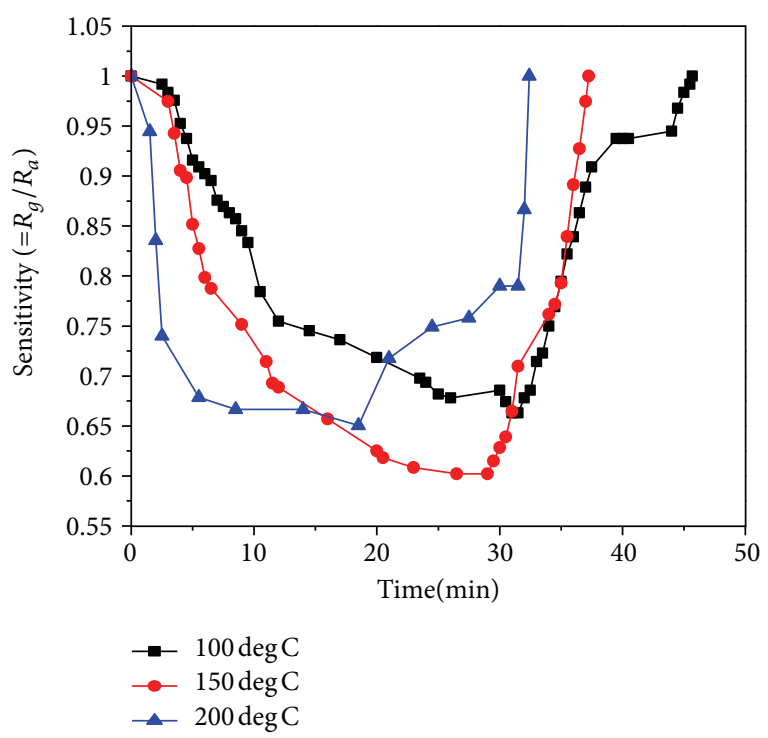

(b)

FIGURE 13: Sensing and recovering response for RDX: (a) $\mathrm{ZnO}$ nanorods (NRs) film F1 and (b) ZnO nanopolypods (NPPs) film F2.

offer a highly sensitive platform for the detection of molecular adsorption on their surfaces [35-39]. The chemical reaction of reducing species $\mathrm{CH}_{3} / \mathrm{CH}_{2}$ present in the TNT/RDX molecule with the adsorbed oxygen $\left(\mathrm{O}_{\mathrm{ads}}^{-}\right)$at elevated temperature results in the release of free electrons $\left(e^{-}\right)$, 


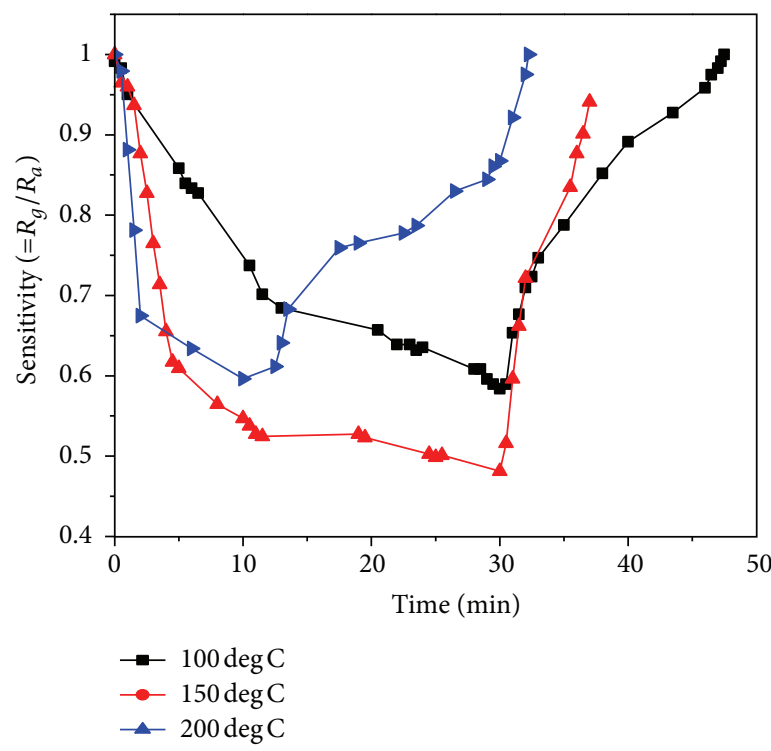

(a)

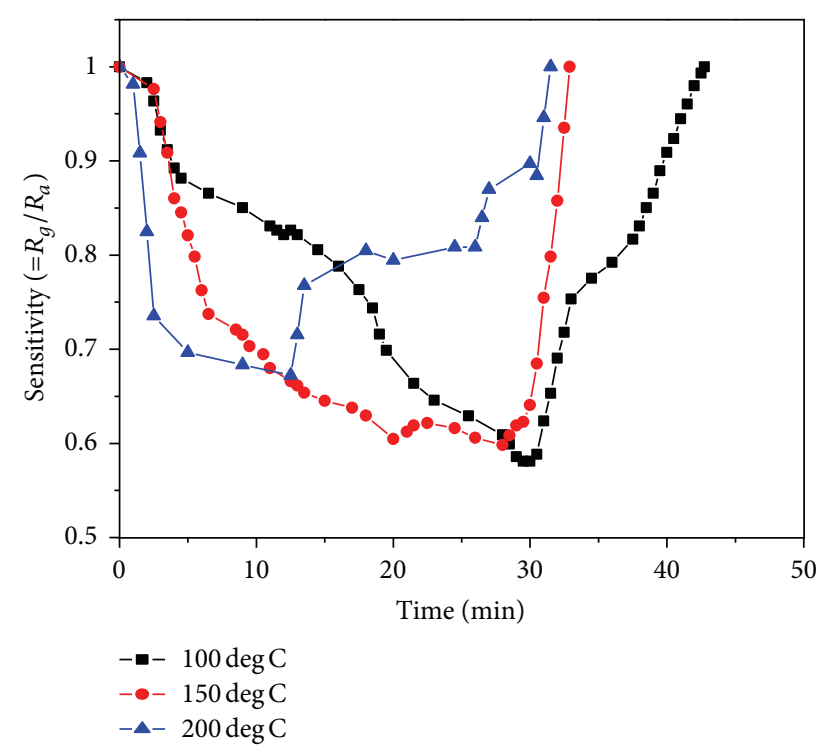

(b)

FIgURE 14: Sensing and recovering response for TNT: (a) ZnO nanorods (NRs) film F1 and (b) ZnO nanopolypods (NPPs) film F2.

TABLE 2: Comparison table of sensitivity $(S \%)$ and recovery time $(t)$ for films F1 and F2 for oxygen.

\begin{tabular}{lcccc}
\hline \multirow{2}{*}{ Temperature $\left({ }^{\circ} \mathrm{C}\right)$} & \multicolumn{2}{c}{ ZnO nanorods (NRs) (F1) } & \multicolumn{2}{c}{ ZnO nanopolypods (NPPs) (F2) } \\
\cline { 2 - 5 } & Percentage of sensor sensitivity (S\%) & Recovery time (min) & Percentage of sensor sensitivity (S\%) & Recovery time (min) \\
\hline 100 & 45.4 & 13.5 & 25 & 15.5 \\
150 & 38.8 & 5.65 & 33.5 & 4.5 \\
200 & 20.2 & 2.75 & 17.7 & 1.4 \\
250 & 34.6 & 0.85 & 14 & 0.6 \\
300 & 28.2 & 0.95 & - & - \\
\hline
\end{tabular}

therefore reducing the resistance of $\mathrm{ZnO}$ nanostructure film. For the experiment $0.2 \mathrm{mg}$ quantity of TNT grains/RDX powder was used for explosive sensing using samples S1 and S2. Additionally, after placing TNT/RDX powder inside the airtight glass chamber, $0.2 \mathrm{BHP}$ rotary suction pump connected to the chamber base was run for $10 \mathrm{~min}$ to drain out atmospheric air from the chamber to create vacuum of $\sim 220 \mathrm{~mm}$ of $\mathrm{Hg}$ pressure below atmosphere. As the vapor pressure of target explosives is very low, the use of vacuum condition for the experiment might have been useful in improving sensor sensitivity to detect low vapour pressure TNT/RDX explosive molecules available inside the airtight chamber.

5.2. Effect of Temperature on Sensor Response for TNT and $R D X$. Figure 12 shows the sensor response of film $\mathrm{F} 1$ in the presence of TNT and RDX in the temperature range from $30^{\circ} \mathrm{C}$ to $210^{\circ} \mathrm{C}$. The sensitivity $(S)$ of sensor was found to decrease gradually with temperature from $30^{\circ} \mathrm{C}$ to $157^{\circ} \mathrm{C}$ in the presence of TNT and from $30^{\circ} \mathrm{C}$ to $172^{\circ} \mathrm{C}$ in the presence of RDX and then nearly stabilize with higher temperature.
The decrease in sensitivity response with the increase in temperature indicates the rate of desorption of reducing gas species present in TNT and RDX as per (6). This results in the increase of conductivity or the decrease of resistance, while in the stabilized region, the activation energy may be enough to complete the chemical reaction.

5.3. Sensor Recovery Analysis for TNT/RDX. The response of films F1 and F2 to a quantity of $0.2 \mathrm{mg}$ of RDX/TNT as explosive source placed for $30 \mathrm{~min}$ inside an airtight chamber and thereafter recovery in air were measured at different temperatures of $100^{\circ} \mathrm{C}, 150^{\circ} \mathrm{C}$, and $200^{\circ} \mathrm{C}$. Figures $13(\mathrm{a}), 13(\mathrm{~b})$, 14(a), and 14(b) show the sensing and recovery time plots for films F1 and F2 in the presence of RDX and TNT, respectively. The sensitivity $(S)$ for both samples decreased during exposure to RDX/TNT over a period of $30 \mathrm{~min}$ at different temperatures due to desorption process of the reducing gas species present in RDX/TNT. After $30 \mathrm{~min}$, the recovery time was found to decrease with the increase in operation temperature. Tables 3 and 4 show the comparison 
TABle 3: Comparison table of sensitivity $(S \%)$ and recovery time $(t)$ for films F1 and F2 for RDX.

\begin{tabular}{lcccc}
\hline \multirow{2}{*}{ Temperature $\left({ }^{\circ} \mathrm{C}\right)$} & \multicolumn{2}{c}{ ZnO nanorods (NRs) (F1) } & \multicolumn{2}{c}{ ZnO nanopolypods (NPPs) (F2) } \\
& Percentage of sensor sensitivity (S\%) & Recovery time (min) & Percentage of sensor sensitivity (S\%) & Recovery time (min) \\
\hline 100 & 54.16 & 11 & 31.42 & 15.7 \\
150 & 49.54 & 3.55 & 37.2 & 7.25 \\
200 & 28 & 1.75 & 21 & 2.4 \\
\hline
\end{tabular}

TABLE 4: Comparison table of sensitivity $(S \%)$ and recovery time $(t)$ for films F1 and F2 for TNT.

\begin{tabular}{lcccc}
\hline \multirow{2}{*}{ Temperature $\left({ }^{\circ} \mathrm{C}\right)$} & \multicolumn{2}{c}{ ZnO nanorods (NRs) (F1) } & \multicolumn{2}{c}{ ZnO nanopolypods (NPPs) (F2) } \\
& Percentage of sensor sensitivity (S\%) & Recovery time (min) & Percentage of sensor sensitivity (S\%) & Recovery time (min) \\
\hline 100 & 41.62 & 17.5 & 42 & 12.75 \\
150 & 51.9 & 7.5 & 36 & 2.9 \\
200 & 13.4 & 2.25 & 10.3 & 1.5 \\
\hline
\end{tabular}

of sensitivity $(S \%)$ and recovery time $(t)$ of films F1 and F2 for both RDX and TNT explosives.

\section{Conclusions}

Uniform array of aligned $\mathrm{ZnO}$ NRs with diameter of about $3100-150 \mathrm{~nm}$ and length of $0.5-1 \mu \mathrm{m}$ and ZnO NRs/NPPs with pod diameter of about $150-200 \mathrm{~nm}$ and length of about $1.5-2 \mu \mathrm{m}$ were grown on glass substrates with microwaveassisted wet chemical synthesis (with capping and without capping agents). Use of triethanolamine as capping agent has resulted in the additional growth of $\mathrm{ZnO}$ NPPs. The structural analysis showed hexagonal wurtzite structure of $\mathrm{ZnO}$ nanostructure with planes highly oriented along (002) direction. The sensing study of $\mathrm{ZnO}$ NRs and $\mathrm{ZnO}$ NRs/NPPs samples showed that the sensor response $(S)$ increases with temperature for both LPG and oxygen, while with the increase in gas concentration from 0.2 to $0.4 \mathrm{vol} \%$, the sensor response increases gradually and attains saturation for LPG, while for oxygen, the response was found to be linear with the increase in gas concentration. The sensor sensing and the recovery time analysis showed that the recovery time reduces with the increase in operation temperature for both gas and explosives. The recovery time of both samples has been found to be the least at the operation temperature of $250^{\circ} \mathrm{C}$ for LPG/oxygen and $200^{\circ} \mathrm{C}$ for TNT/RDX. Additionally the recovery time achieved for LPG at 0.4 vol\% concentration in this study is much lesser than that previously reported for $\mathrm{ZnO}$ thin film with much higher LPG concentration. The present work shows that both $\mathrm{ZnO}$ NRs and $\mathrm{ZnO}$ NRs/NPPs have excellent potential for both gas and explosive sensing applications.

\section{Acknowledgments}

The author is thankful to the Vice-Chancellor, DIAT(DU), Pune and Director of ARDE, Pune, for granting permission to publish this work. The author would like to acknowledge Department of Physics, University of Pune, and C-MET,
Pune, for providing SEM facilities and HEMRL, Pune, for providing XRD facilities.

\section{References}

[1] C. R. Gorla, N. W. Emanetoglu, S. Liang et al., "Structural, optical, and surface acoustic wave properties of epitaxial $\mathrm{ZnO}$ films grown on (0112) sapphire by metalorganic chemical vapor deposition," Journal of Applied Physics, vol. 85, no. 5, pp. 2595$2602,1999$.

[2] X. D. Wang, C. J. Summers, and Z. L. Wang, "Large-scale hexagonal-patterned growth of aligned $\mathrm{ZnO}$ nanorods for nanooptoelectronics and nanosensor arrays," Nano Letters, vol. 4, no. 3, pp. 423-426, 2004.

[3] S. B. Patil and A. K. Singh, "Solution grown nanocrystalline $\mathrm{ZnO}$ thin films for UV emission and LPG sensing," Journal of Materials Science, vol. 45, no. 19, pp. 5204-5210, 2010.

[4] V. R. Shinde, T. P. Gujar, and C. D. Lokhande, "LPG sensing properties of $\mathrm{ZnO}$ films prepared by spray pyrolysis method: effect of molarity of precursor solution," Sensors and Actuators $B$, vol. 120, no. 2, pp. 551-559, 2007.

[5] B. Ismail, M. Abaab, and B. Rezig, "Structural and electrical properties of $\mathrm{ZnO}$ films prepared by screen printing technique," Thin Solid Films, vol. 383, no. 1-2, pp. 92-94, 2001.

[6] X. Q. Liu, S. W. Tao, and Y. S. Shen, "Preparation and characterization of nanocrystalline $\alpha$ by sol-gel process," Sensors and Actuators B, vol. 40, no. 2-3, pp. 161-165, 1997.

[7] A. P. Chatterjee, P. Mitra, and A. K. Mukhopadhyay, "Chemically deposited zinc oxide thin film gas sensor," Journal of Materials Science, vol. 34, no. 17, pp. 4225-4231, 1999.

[8] W. Y. Feng, N. Chiu, H. Lu, H. Shih, D. Yang, and C. Lin, "Surface plasmon resonance biochip based on $\mathrm{ZnO}$ thin film for nitric oxide sensing," in Proceedings of the 30th Annual International Conference of the IEEE Engineering in Medicine and Biology Society (EMBS'08), Vancouver, Canada, August 2008.

[9] L. Satyanarayana, K. M. Reddy, and S. V. Manorama, "Nanosized spinel $\mathrm{NiFe}_{2} \mathrm{O}_{4}$ : a novel material for the detection of liquefied petroleum gas in air," Materials Chemistry and Physics, vol. 82, no. 1, pp. 21-26, 2003. 
[10] Z. P. Sun, L. Liu, L. Zhang, and D. Z. Jia, "Rapid synthesis of ZnO nanorods by one step-room temperature solid state reaction and their gas sensing properties," Nanotechnology, vol. 17, no. 9, pp. 2266-2270, 2006.

[11] Z. R. Dai, Z. W. Pan, and Z. L. Wang, "Novel nanostructures of functional oxides synthesized by thermal evaporation," Advanced Functional Materials, vol. 13, no. 1, pp. 9-24, 2003.

[12] Z. Q. Liu, D. H. Zhang, S. Han et al., "Laser ablation synthesis and electron transport studies of tin oxide nanowires," Advanced Materials, vol. 15, no. 20, pp. 1754-1757, 2003.

[13] W. I. Park, D. H. Kim, S. W. Jung, and G. C. Yi, "Metalorganic vapor-phase epitaxial growth of vertically well-aligned $\mathrm{ZnO}$ nanorods," Applied Physics Letters, vol. 80, no. 22, pp. 42324236, 2002.

[14] S. Y. Bae, H. W. Seo, and J. Park, "Vertically aligned sulfur-doped $\mathrm{ZnO}$ nanowires synthesized via chemical vapor deposition," Journal of Physical Chemistry B, vol. 108, no. 17, pp. 5206-5210, 2004.

[15] B. Liu and H. C. Zeng, "Hydrothermal synthesis of ZnO nanorods in the diameter regime of $50 \mathrm{~nm}$," Journal of the American Chemical Society, vol. 125, no. 15, pp. 4430-4431, 2003.

[16] J. M. Wang and L. Gao, "Wet chemical synthesis of ultralong and straight single-crystalline $\mathrm{ZnO}$ nanowires and their excellent UV emission properties," Journal of Materials Chemistry, vol. 13, no. 10, pp. 2551-2554, 2003.

[17] M. K. Hossain, S. C. Ghosh, Y. Boontongkong, C. Thanachayanont, and J. Dutta, "Growth of zinc oxide nanowires and nanobelts for gas sensing applications," Journal of Metastable and Nanocrystalline Materials, vol. 23, pp. 27-30, 2005.

[18] A. K. Singh and V. S. Raykar, "Microwave synthesis of silver nanofluids with polyvinylpyrrolidone (PVP) and their transport properties," Colloid and Polymer Science, vol. 286, no. 14-15, pp. 1667-1673, 2008.

[19] C. C. Li, Z. F. Du, L. M. Li, H. C. Yu, Q. Wan, and T. H. Wang, "Surface-depletion controlled gas sensing of $\mathrm{ZnO}$ nanorods grown at room temperature,", Applied Physics Letters, vol. 91, no. 3, Article ID 032101, 3 pages, 2007.

[20] J. X. Wang, X. W. Sun, Y. Yang et al., "Hydrothermally grown oriented $\mathrm{ZnO}$ nanorod arrays for gas sensing applications," Nanotechnology, vol. 17, no. 19, pp. 4995-4998, 2006.

[21] Y. Lv, L. Guo, H. Xu, and X. Chu, "Gas-sensing properties of well-crystalline $\mathrm{ZnO}$ nanorods grown by a simple route," Physica E, vol. 36, no. 1, pp. 102-105, 2007.

[22] H. Zhang, J. Wu, C. Zhai, N. Du, X. Ma, and D. Yang, "From $\mathrm{ZnO}$ nanorods to $3 \mathrm{D}$ hollow microhemispheres: solvothermal synthesis, photoluminescence and gas sensor properties," Nanotechnology, vol. 18, no. 45, Article ID 455604, 2007.

[23] C. Baratto, G. Sberveglieri, A. Onischuk, B. Caruso, and S. Di Stasio, "Low temperature selective $\mathrm{NO}_{2}$ sensors by nanostructured fibres of ZnO," Sensors and Actuators B, vol. 100, no. 1-2, pp. 261-265, 2004.

[24] G. Kenanakis, D. Vernardou, E. Koudoumas, G. Kiriakidis, and N. Katsarakis, "Ozone sensing properties of $\mathrm{ZnO}$ nanostructures grown by the aqueous chemical growth technique," Sensors and Actuators B, vol. 124, no. 1, pp. 187-191, 2007.

[25] K. J. Choi and H. W. Jang, "One-dimensional oxide nanostructures as gas-sensing materials: review and issues," Sensors, vol. 10, no. 4, pp. 4083-4099, 2010.

[26] W. T. Wu, L. Shi, Q. Zhu, Y. Wang, G. Xu, and W. Pang, "Rapid synthesis of $\mathrm{ZnO}$ micro/nanostructures in large scale," Materials Letters, vol. 62, no. 1, pp. 159-162, 2008.
[27] H. Gong, J. Q. Hu, J. H. Wang, C. H. Ong, and F. R. Zhu, "Nanocrystalline $\mathrm{Cu}$-doped $\mathrm{ZnO}$ thin film gas sensor for CO," Sensors and Actuators B, vol. 115, no. 1, pp. 247-251, 2006.

[28] A. K. Singh, V. Viswanath, and V. C. Janu, "Synthesis, effect of capping agents, structural, optical and photoluminescence properties of $\mathrm{ZnO}$ nanoparticles," Journal of Luminescence, vol. 129, no. 8, pp. 874-878, 2009.

[29] Y. L. Wu, A. I. Y. Tok, F. Y. C. Boey, X. T. Zeng, and X. H. Zhang, "Chemical synthesis of $\mathrm{ZnO}$ nanocrystals," IEEE Transactions on Nanotechnology, vol. 6, no. 5, pp. 497-503, 2006.

[30] A. Ghosh, N. G. Deshpande, Y. G. Gudage et al., "Effect of annealing on structural and optical properties of zinc oxide thin film deposited by successive ionic layer adsorption and reaction technique," Journal of Alloys and Compounds, vol. 469, no. 1-2, pp. 56-60, 2009.

[31] K. Thongsuriwong, P. Amornpitoksuk, and S. Suwanboon, "The effect of aminoalcohols (MEA, DEA and TEA) on morphological control of nanocrystalline $\mathrm{ZnO}$ powders and its optical properties," Journal of Physics and Chemistry of Solids, vol. 71, no. 5, pp. 730-734, 2010.

[32] D. R. Patil, L. A. Patil, G. H. Jain, M. S. Wagh, and S. A. Patil, "Surface activated $\mathrm{ZnO}$ thick film resistor for LPG gas sensing," Sensor and Transducer Journal, vol. 74, no. 12, pp. 874-883, 2006.

[33] A. D. Garje and R. C. Aiyer, "Electrical and gas-sensing properties of a thick film resistor of nanosized $\mathrm{SnO}_{2}$ with variable percentage of permanent binder," International Journal of Applied Ceramic Technology, vol. 3, no. 6, pp. 477-484, 2006.

[34] L. Senesac and T. G. Thundat, "Nanosensors for trace explosive detection," Materials Today, vol. 11, no. 3, pp. 28-36, 2008.

[35] F. Patolsky and C. M. Lieber, "Nanowire nanosensors," Materials Today, vol. 8, no. 4, pp. 20-28, 2005.

[36] N. Grobert, "Carbon nanotubes-becoming clean," Materials Today, vol. 10, no. 1-2, pp. 28-35, 2007.

[37] B. L. Allen, P. D. Kichambare, and A. Star, "Carbon nanotubes FET based biosensors," Advanced Materials, vol. 19, no. 11, pp. 1439-1451, 2007.

[38] Y. Cui, X. Duan, Y. Huang, and C. M. Lieber, Nanowires and Nanobelts-Materials, Properties and Devices, edited by Z. L. Wang, Kluwer Academic/Plenum, Dordrecht, The Netherlands, 2003.

[39] Z. L. Wang, "Nanostructures of ZnO," Materials Today, vol. 7, no. 6, pp. 26-33, 2004. 

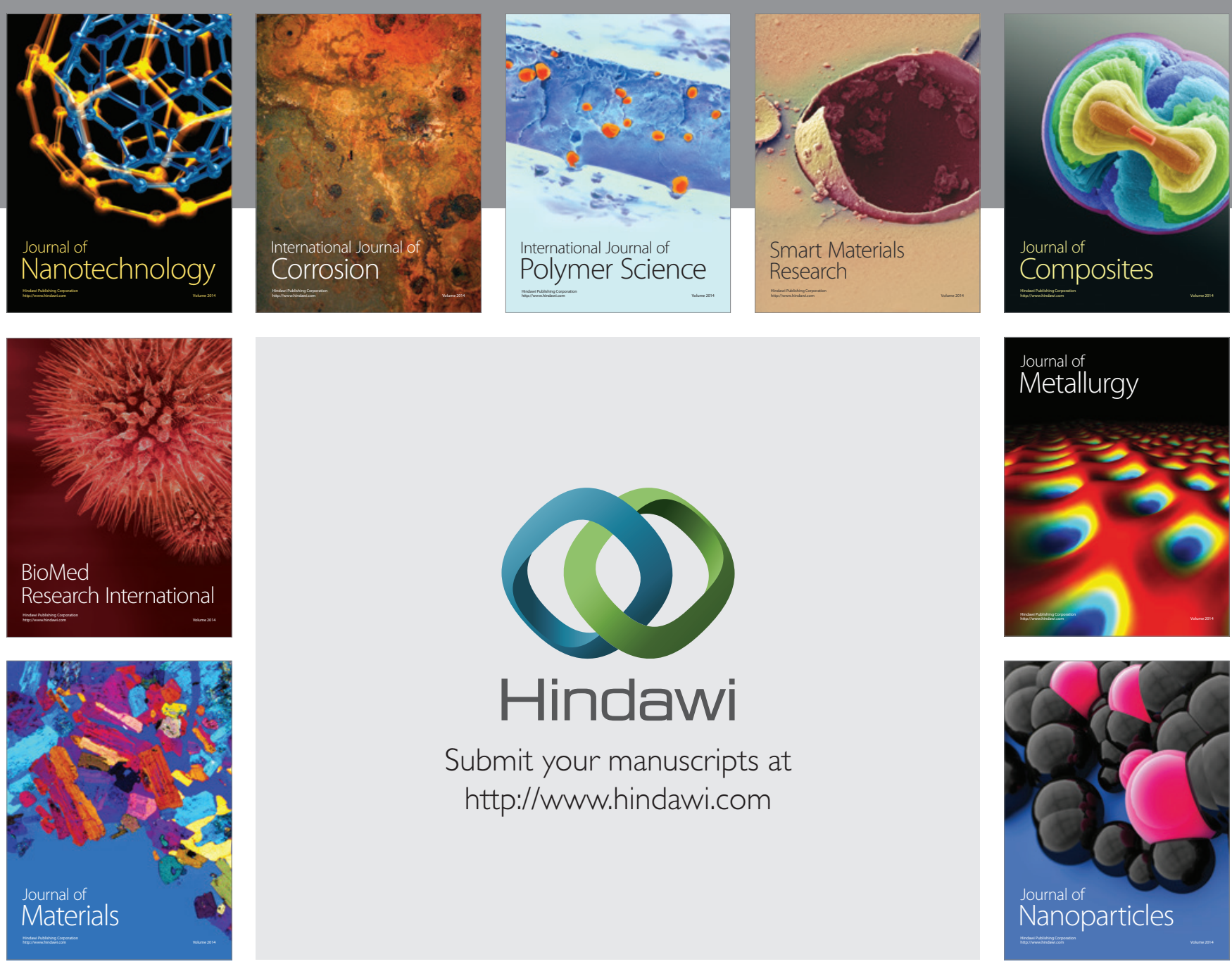

Submit your manuscripts at http://www.hindawi.com
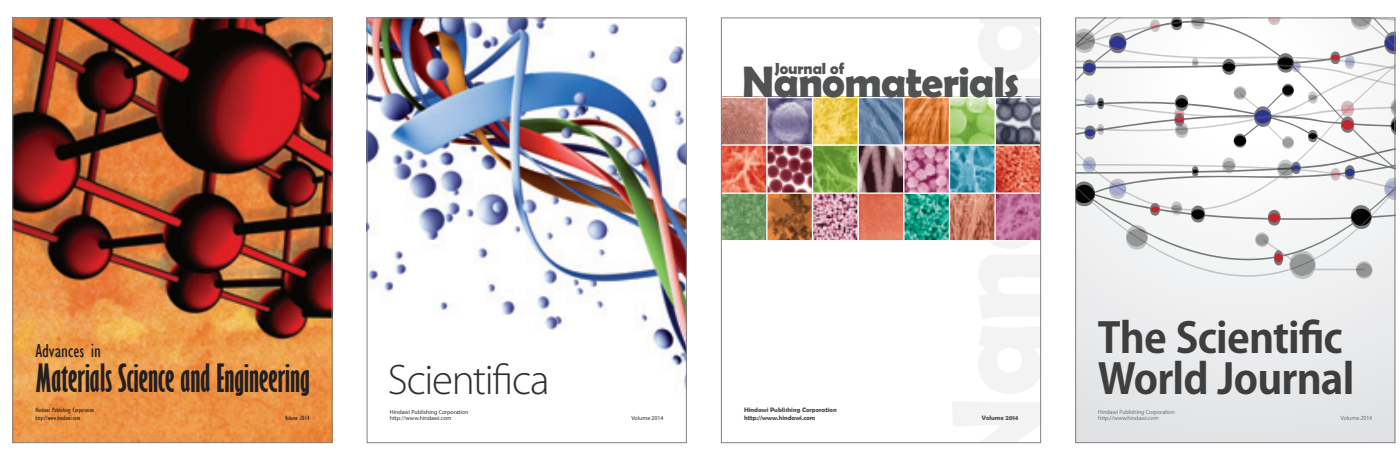

\section{The Scientific World Journal}
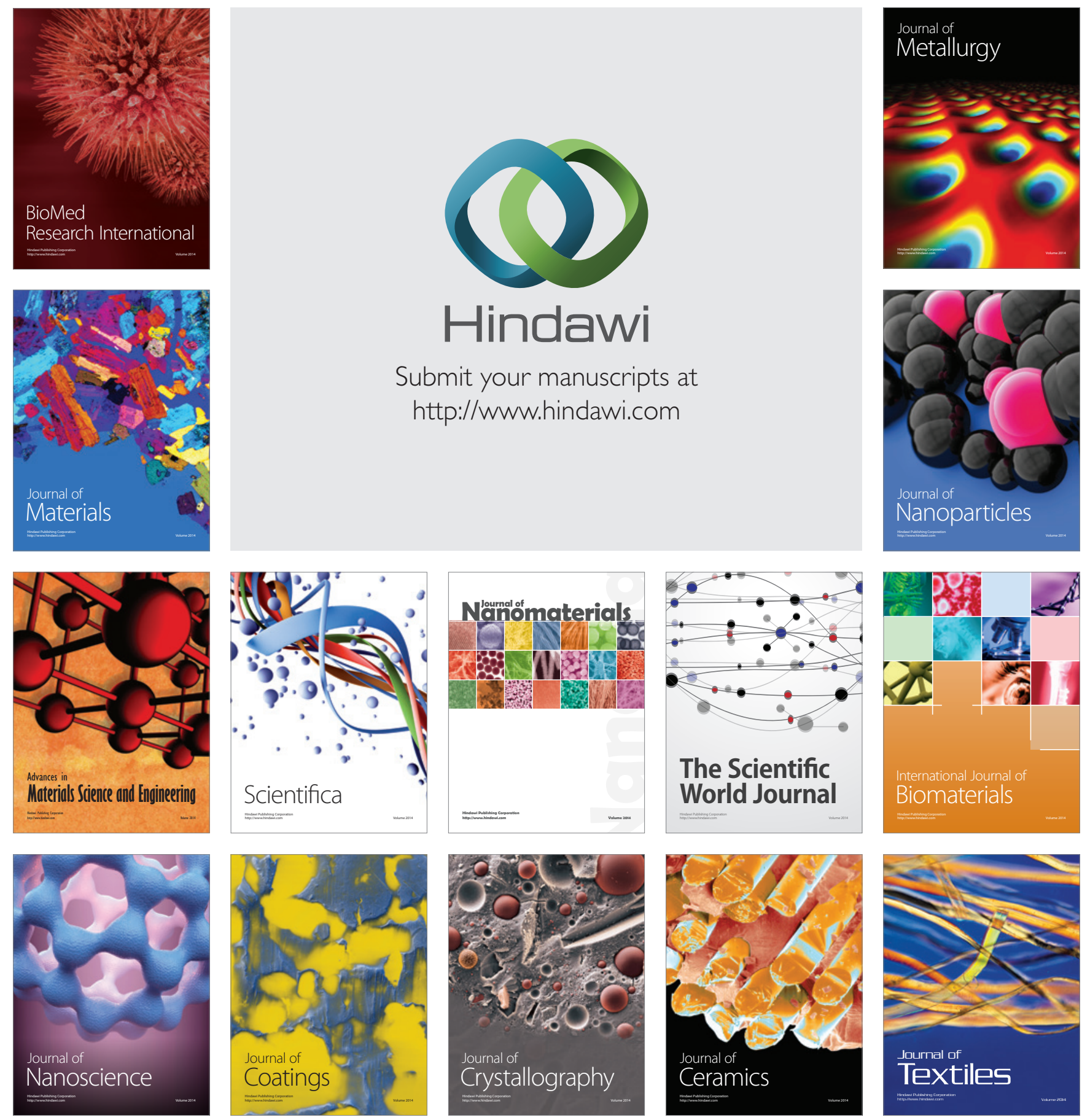